\title{
Investigation on the Electrical Conductivity of PZT Modified by Manganese and Cerium
}

\author{
Balgovind Tiwari ${ }^{1}$, T. Babu ${ }^{2}$, R.N.P. Choudhary ${ }^{3}$ \\ ${ }^{1}$ Assistant Professor, Dept. of Physics, IIIT-RKValley, RGUKT, A.P., India \\ ${ }^{2}$ Teacher, Dept. of Physics, Sri Chaitanya High School, Vempalli, Kadapa, A.P., India \\ ${ }^{3}$ Professor, Dept. of Physics, ITER-SOA University, Bhubaneswar, Orissa, India \\ balgovindtiwari@gmail.com ${ }^{l}$
}

\begin{abstract}
PZT is a ferroelectric ceramic material that has acquired immense importance in the field of electronics industry. The main focus of this report is to present the electrical conductivity response of manganese and cerium modified lead zirconatetitanate (PZT). The conductivity response has been investigated with respect to frequency of applied ac electric field and temperature. The samples have been prepared by mixing high purity chemicals, through high temperature solid state route. The frequency response of electrical conductivity has been analysed on the basis of Maxwell-Wagner and Koop's model. The temperature response of electrical conductivity indicated that the compounds exhibit Arrhenius behaviour.
\end{abstract}

\section{Keywords:Ceramic; conduction; PZT; Solid state;}

\section{Introduction}

Lead zirconatetitanate belongs to ferroelectric materials that can exist in ceramic form. It possess a tremendous and an intensified electrical property i.e. ferroelectricity, even when the applied ac electric filed is removed [1]. Hence the PZT has been, and is still being used in wide range of electrical applications such as capacitive and resistive elements in electronic circuits, piezosensors, actuators, etc [2-3]. The increasing importance of PZT, since its discovery in 1952, is mainly due to its stability over wide temperature domain. Further, it has been observed from several studies that PZT possess large values of polarization, high coupling coefficients, appreciable thermal stability, etc. especially at morphotropical phase boundary (MPB). MPB can be considered as one of the composition of PZT where it shows the mixed phase, and it usually exists when the amount of zirconium/titanium $(\mathrm{Zr} / \mathrm{Ti})$ is nearly and/or exactly same [4].PZT, being a family member of $\mathrm{ABO}_{3}$ perovskites, possess large sized cations $\left(\mathrm{Pb}^{+2}\right.$ ions) at $\mathrm{A}$ site (i.e. at corners of the unit cell) and small sized cations $\left(\mathrm{Zr}^{+4} / \mathrm{Ti}^{+4}\right.$ ions) at the $\mathrm{B}$ site (i.e. at center of the unit cell). The oxygen atoms are situated at the faces of unit cell [5-6].

The conductivity of ferroelectric material can be investigated based on its response to external ac electric signal. The conduction that takes place in ferroelectrics is mainly due to the charge carriers that are weakly bounded. When an electric field is applied, the ordered motion of charged particles results in electrical conduction. Since ferroelectrics are assumed not to have free charge carriers, the existence of conductivity is may be due to low mobile ionic charges. Hence, the conduction in ferroelectrics takes place through hopping of charge carriers [7]. Using parameters of dielectric information, the conductivity has been calculated from the following expression:

$\sigma_{\mathrm{ac}}=\omega \varepsilon_{\mathrm{r}} \varepsilon_{0} \tan \delta$

where $\varepsilon_{0}$ permittivity in free space, and $\omega$ angular frequency. The ac conductivity of a material can be investigated as a function of frequency, based 
on Jonscher's power law [8]:

$$
\begin{aligned}
& \sigma_{\mathrm{T}}(\omega)=\sigma(0)+\sigma_{1}(\omega) \\
& \sigma_{\mathrm{T}}(\omega)=\sigma_{0}+a \omega^{n}
\end{aligned}
$$

where $\sigma(0)$ is the conductivity that is independent on frequency and $\sigma_{1}(\omega)$ is the ac conductivity that is dependent on frequency. The conductivity of a material can be obtained by dividing the magnitudes of steady state current with the voltage applied. The behavior of conductivity of a material can be studied as a function of temperature, based on the following relation [8]:

$$
\sigma=A \exp .\left(-\frac{E_{a}}{k T}\right)+B \exp .\left(-\frac{E_{b}}{k T}\right)
$$

where $E_{a}$ activation energy for intrinsic conduction and $\mathrm{E}_{\mathrm{b}}$ corresponds extrinsic conduction process. The above mentioned relation ca be reduced, when the intrinsic conduction dominates the extrinsic conduction, to the following [9]:

$$
\sigma=A \exp \cdot\left(-\frac{E_{a}}{k T}\right) \text {. }
$$

Our extensive literature survey indicated lots of works on $\mathrm{Mn} / \mathrm{Ce}$ modified PZT ceramics [12-19] but very few on PZT ceramics of 35/65 composition PZT. Recently, a work on the effect of $\mathrm{Ce}$ on electrical properties of 52/48 PZT has been reported [20]. It has been reported that $\mathrm{Ce}$ modified compounds exhibit large values of $\mathrm{T}_{\mathrm{c}}$, small values of $\tan \delta$ and high impedance, etc. The electromechanical coefficient of 50/50 PZT has been increased, on the addition of $\mathrm{MnO}_{2}$ [21]. PZT thin film, doped with $\mathrm{Mn}$ and $\mathrm{Sb}$, has been suggested for IR detectors due to good IR sensitivity and high pyroelectric coefficient [22]. It is also observed that there is change in the size, shape and distribution of grains, over the surfaces of Ce modified 65/35 PZT [23].

The conductivity nature PZT, PZMT and PZCT samples has been studied, and presented in this paper. The samples have been electrically characterized with LCR meter, the recorded data has been further evaluated to find the magnitude of ac electrical conductivity.

\section{Experimental Section}

The inorganic oxides of $99.9 \%$ purity were used to prepare the samples of $\mathrm{Pb}\left(\mathrm{Zr}_{0.52-\mathrm{x}} \mathrm{Y}_{\mathrm{x}} \mathrm{Ti}_{0.48}\right) \mathrm{O}_{3}(\mathrm{x}=$ $0.00,0.10$ and $\mathrm{Y}=\mathrm{Mn} / \mathrm{Ce})$. The complete procedure and process parameters are similar to that, which have been reported elsewhere [22-23].

\section{Results and Discussion}

\subsection{Variation of ac conductivity with frequency}

The fluctuation of ac conductivity of as prepared samples with frequency, is shown in Figure 1 (ad).

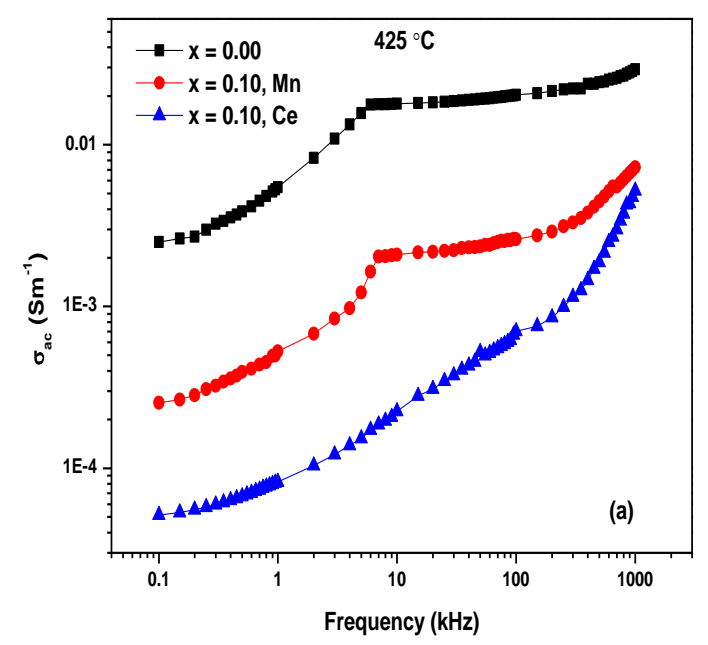

Fig.1.
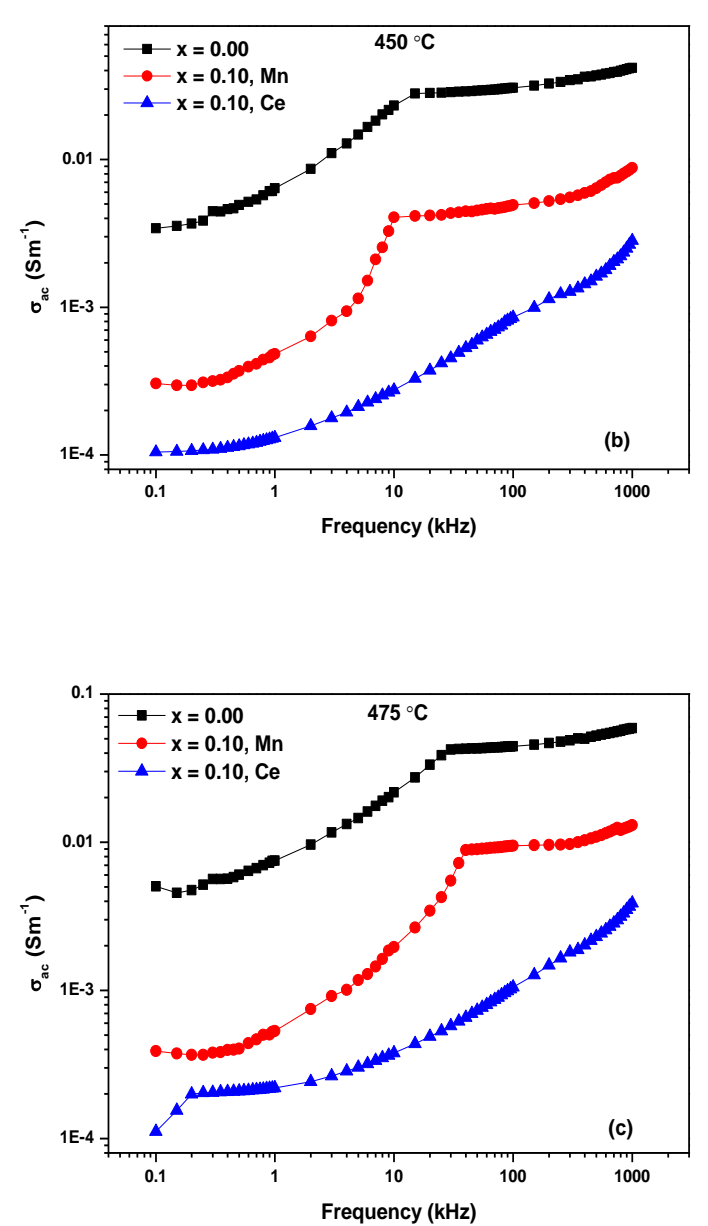


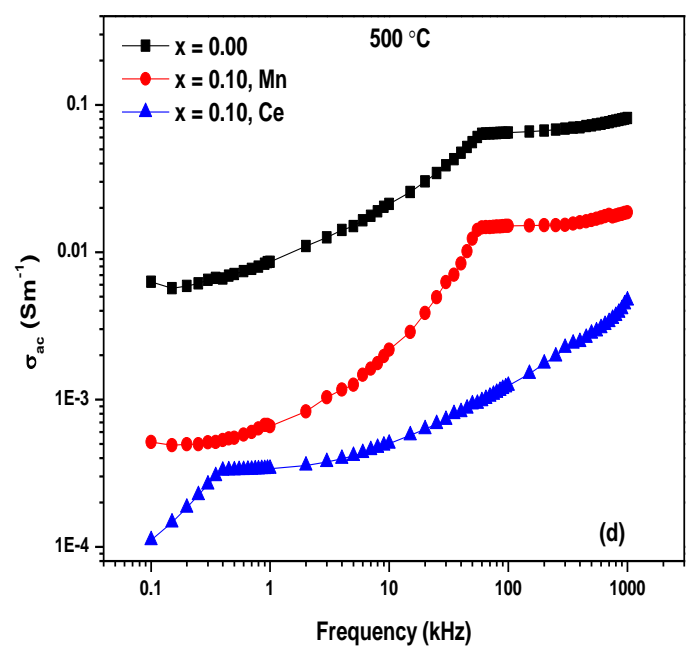

Fig.1 (a-d). Variation of ac conductivity with frequency

With rise in frequency, the magnitude of ac conductivity is increasing. At a particular frequency, there is slight discontinuity in the variation of conductivity. The frequency at which this discontinuity takes place can considered as the hopping frequency. The presence of hopping frequency can be related to the negligible contribution of space charge polarization. Except for PZCT at $475{ }^{\circ} \mathrm{C}$ and $500{ }^{\circ} \mathrm{C}$, all the samples exhibit the hopping frequency in the region of high frequency. This is sensible because the space charges get released at higher temperatures as well as at higher frequencies. According to MaxwellWagner and Koop's theoretical models, bulk part i.e. grains are more active than grain boundaries at higher frequencies [3]. Due to the application of low frequency electric field, the electrons tend to aggregate at the grain boundaries. Increment in the frequency of the filed results in the stoppage of electrons flow, and hence the reduced space charge polarization. The negligible space charge polarization at higher frequencies further indicate the reduction in barrier properties of the materials. Also, the frequencies of hopping are observed to be dependent on temperature due to their shift towards high frequencies with rise in temperature. Hence, conduction is governed by Jonscher's power law [19]. Below the hopping frequency, the conduction can be attributed to the charges that may present at grain boundaries. Above the hopping frequency, grains start dominating the grain boundaries and hence the change in slope takes place. At $475{ }^{\circ} \mathrm{C}$ and $500{ }^{\circ} \mathrm{C}$, PZCT exhibit hopping frequencies at lower frequencies only. This could mean that the grains might be active at low frequencies due to increase in temperature.

\subsection{Variation of ac conductivity with inverse absolute of temperature}

The fluctuation of ac conductivity with temperature, is shown in figure $2(\mathrm{a}-\mathrm{c})$.
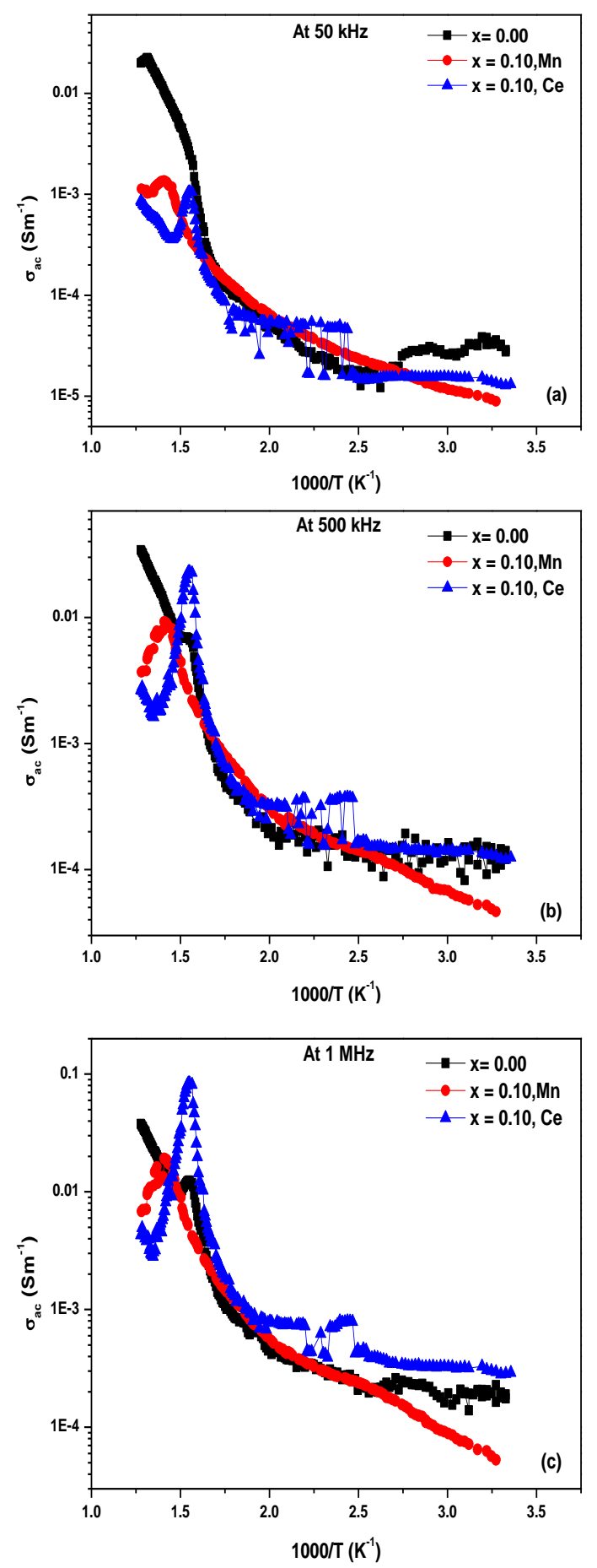

Fig.2 (a-c). Variation of ac conductivity with temperature 
It can be observed from the figure that the magnitude ac conductivity of all samples shows significant variation over wide range of temperatures. With rise in temperature, the conductivity of all samples in increasing indicating the presence of peaks at higher temperatures. These peaks correspond to the dielectric relaxation peaks that can observed near Curie temperature region [7, 23]. The increment in conductivity with rise in temperature suggests the semiconducting nature i.e. negative coefficient of resistance behavior. The existence of conduction in the materials can be attributed to the hopping charge carriers. Hence, the increment in ac conductivity with temperature indicate the increase in rate of hopping of charge carriers with temperature. Hence, the nature of graphs suggests that the transport properties of materials are thermally activated obeying Arrhenius law. When the temperature increases, the polarons become active since they get the required thermal energy and jump over the grain boundaries [24]. Different slopes of the graphs indicate different activation energies of the compounds.

\section{Conclusions}

In this work, the electrical conduction mechanism of PZT modified by manganese and cerium has been studied. The samples have been synthesized through standard synthesis technique of ceramics i.e. solid state mixing. The analysis indicated that the ac conductivity of compounds obey Jonscher's power law (over the wide frequency domain) and Arrhenius law (over the wide temperature domain). The enhancement in ac conductivity with temperature suggests that the compounds behave as semiconductor at higher temperatures. The appearance of peaks near higher temperatures indicate evidence of dielectric relaxation. Also, the activation energy of the compound changes with change in temperature and modifier.

\section{Acknowledgement}

We (authors) are grateful for the experimental facilities provided by IIT Kharagpur. We also thak the partial financial support of DST-SERB.

\section{References}

[1] Q. Zhang and R.W. Whatmore (2004). Low Fatigue Lead ZirconateTitanate-based
Capacitors Modified by Manganese for Nonvolatile Memories, Materials Science and Engineering B, 109, 136-140.

[2] Macdonald JR. Impedance Spectroscopy: Emphasizing Solid State Material and Sytems. New York, Wiley; 1987.

[3] Balgovind Tiwari, T. Babu and R.N.P. Choudhary (2020). AC Impedance and Modulus Spectroscopic Studies of $\mathrm{Pb}\left(\mathrm{Zr}_{0.35-\mathrm{x}} \mathrm{Ce}_{\mathrm{x}} \mathrm{Ti}_{0.65}\right) \mathrm{O}_{3} \quad(\mathrm{x}=0.00, \quad 0.05$, $0.10,0.15) \quad$ Ferroelectric Ceramics, Materials Chemistry and Physics, 256, 123655.

[4] Panigrahi SC, Piyush R. Das and Choudhary RNP (2018). Ferroelectric studies for soft Gd-modified PZT ceramics. Phase Transitions, 703-714.

[5] Tiwari B, Babu T and Choudhary RNP (2020). Synthesis of $\mathrm{Pb}\left(\mathrm{Zr}_{0.35}{ }_{x} \mathrm{Mn}_{x} \mathrm{Ti}_{0.65}\right) \mathrm{O}_{3}, \quad \mathrm{x}=0.00, \quad 0.02$, $0.06,0.10$ ceramics and their structural, dielectric characteristics, Materials Research Express, 7, 055701,

[6] P.W. Macmillan, Glass Ceramics, Second Edition, London: Academic Press; 1979.

[7] P.R. Das, Investigations of structural, dielectric and electrical properties of some Tungsten Bronze Ferroelectric Vanadates, Ph.D. Thesis, IIT Kharagpur, India, 2007.

[8] Jonscher AK, Phy. Thin films, 11 (1980), 232.

[9] B. Tiwari (2011). Structural, Dielectric and Electrical Properties of Manganese Modified Lead ZIrconateTitanates with Different Zirconium and Titanium Ratios, Ph.D. Thesis, IIT Kharagpur, India.

[10]Jaffe B, Roth RS, Marzullo S. Piezoelectric Properties of Lead Zirconate- Lead Titanate Solid- Solution Ceramics. Journal of Applied Physics 1954; 25: 809-810.

[11]PelaizBarranco A, Calderon F, Martinez P. Effects of $\mathrm{MnO} 2$ additive on the properties of $\quad \mathrm{PbZrO} 3-\mathrm{PbTiO} 3-\mathrm{PbCu} 1 / 4 \mathrm{Nb} 3 / 4 \mathrm{O} 3$ ferroelectric ceramic system. Journal of the European Ceramic Society 2001; 523-529.

[12]Jaffe B, Roth RS, Marzullo S. Properties of Piezoelectric Ceramics in the SolidSolution Series Lead Titanate-Lead Zirconate-Lead Oxide: Tin Oxide and Lead 
Titanate-Lead Hafnate. J. Res. Natl. Bur. Stand. 1955; 55: 239-248.

[13]Heartling GH, Land CE. Hot- Pressed $(\mathrm{Pb}, \mathrm{La})(\mathrm{Zr}, \mathrm{Ti}) \mathrm{O}_{3}$ Ferroelectric Ceramics for Electrooptic Applications. Journal of American Ceramic Society 1971; 54: 1-11.

[14]Toacsan MI, Ioachim A, Nedelcu L, et al. Accelerate ageing of PZT-type ceramics. Progress in Solid State Chemistry 2007; 35: 531-537.

[15]Shaw CP, Gupta S, Stringfellow SB, et al. Pyroelectric properties of Mn-doped lead zirconate-lead titanate-lead magnesium niobate ceramics. Journal of the European Ceramic Society 2002; 22: 2123-2132.

[16]Qi Zhang, Whatmore RR. Hysteretic properties of $\mathrm{Mn}$-doped $\mathrm{Pb}(\mathrm{Zr}, \mathrm{Ti}) \mathrm{O}_{3}$ thin films. Journal of the European Ceramic Society 2004; 24: 277-282.

[17]Balgovind Tiwari, Choudhary RNP. Complex Impedance Spectroscopic Analysis of $\mathrm{Mn}$ modified $\mathrm{Pb}\left(\mathrm{Zr}_{0.65-}\right.$ $\left.{ }_{\mathrm{x}} \mathrm{Mn}_{\mathrm{x}} \mathrm{Ti}_{0.35}\right) \mathrm{O}_{3}$ Electroceramics. Journal of Physics and Chemistry of Solids 2008; 69: 2852-2857.

[18]Das PR. Investigations of structural, dielectric, electrical properties of some Tungsten Bronze Ferroelectric Vanadates. Ph.D Thesis. IIT-Kharagpur: India; 2007.

[19]Ashok Kumar, Choudhary RNP, Singh BP, et al. Effect of strontium concentration on electrical conduction properties of $\mathrm{Sr}$ modified $\mathrm{BaSnO}_{3}$. Ceramics International 2006; 32: 73-83.

[20]Balgovind Tiwari, Choudhary RNP. Study of Impedance Parameters of Ce modified $\mathrm{Pb}\left(\mathrm{Zr}_{0.65-\mathrm{x}} \mathrm{Ce}_{\mathrm{x}} \mathrm{Ti}_{0.35}\right) \mathrm{O}_{3}$ Ceramics. IEEE Transactions on Dielectrics and Electrical Insulation 2010; 17: 5-17.

[21]BanarjiBehera, Nayak P, Choudhary RNP. Impedance spectroscopy study of $\mathrm{NaBa}_{2} \mathrm{~V}_{5} \mathrm{O}_{15}$ ceramic. Journal of Alloys and Compounds 2007; 436: 226-232.

[22]Balgovind Tiwari, Choudhary RNP. Effect of $\mathrm{mn}$ on structural and dielectric properties of $\mathrm{Pb}\left(\mathrm{Zr}_{0.52} \mathrm{Tti}_{0.48}\right) \mathrm{O}_{3}$ electroceramic. IEEE Transactions on Dielectrics and Electrical Insulation 2015; 22: 3046-3052.
[23]Tiwari B, Babu T, Choudhary RNP. Dielectric, impedance and modulus spectroscopy of $\mathrm{Pb}\left(\mathrm{Zr}_{0.52-\mathrm{x}} \mathrm{Ce}_{\mathrm{x}} \mathrm{Ti}_{0.48}\right) \mathrm{O}_{3}(\mathrm{x}=$ $0.00, \quad 0.10) \quad$ ferroelectric ceramics.PhysicaScripta 2020;95: 115806.

[24]Tiwari B, Babu T, Choudhary RNP. Conduction Studies of $\mathrm{Pb}\left(\mathrm{Zr}_{0.35-}\right.$ $\left.{ }_{\mathrm{x}} \mathrm{Y}_{\mathrm{x}} \mathrm{Ti}_{0.65}\right) \mathrm{O}_{3} \quad(\mathrm{x}=0.00,0.10$ and $\mathrm{Y}=$ $\mathrm{Mn} / \mathrm{Ce})$ Ceramics. International Research Journal on Advanced Science Hub2020;2: 55-58. 